Research Article

\title{
Challenges Faced by the Development Support Group in Implementing the Integrated Quality Management System in Circuit 04 Schools in the Mthatha Education District
}

\author{
Simon Adjei Tachie $\mathbb{D}^{1}$ and Nandi Carol Mancotywa ${ }^{2}$ \\ ${ }^{1}$ School of Mathematics, Science and Technology Education in the Faculty of Education, North-West University, \\ Potchefstroom, South Africa \\ ${ }^{2}$ Department of Education, Walter Sisulu University, Mthatha 5011, South Africa
}

Correspondence should be addressed to Simon Adjei Tachie; simon.tachie@gmail.com

Received 5 September 2020; Revised 26 August 2021; Accepted 6 September 2021; Published 22 September 2021

Academic Editor: Ehsan Namaziandost

Copyright (C) 2021 Simon Adjei Tachie and Nandi Carol Mancotywa. This is an open access article distributed under the Creative Commons Attribution License, which permits unrestricted use, distribution, and reproduction in any medium, provided the original work is properly cited.

\begin{abstract}
The purpose of this study was to investigate challenges faced by Development Support Groups (DSGs) in implementing the Integrated Quality Management System (IQMS) in the primary schools of Circuit 04 of the Mthatha District of the Eastern Cape Province, South Africa. The scope of this research was restricted to four primary schools in Circuit 04 . The research methodology was qualitative in nature, and a multiple case study strategy was employed. The sampling strategy was convenience sampling and included DSGs and teachers. Data were collected through face-to-face individual in-depth interviews to elicit information from DSGs and teachers. The IQMS is performed through the completion of special instruments, which help to rate and score teachers on their performances. During IQMS, two structures, the DSGs and School Development Team (SDT), are created to implement developmental appraisal and performance management (or summative evaluation). The main finding of this study revealed that even though school principals were part of the team and structure to manage the IQMS, some principals did not drive or influence the process resulting in some schools finding it difficult to effectively manage the IQMS. Challenges, thus, faced by DSGs tended to have a negative effect on the teachers as well as on learner performance.
\end{abstract}

\section{Introduction}

The Integrated Quality Management System (IQMS) is a national policy in South Africa aimed at increasing productivity among educators in the South African education system. The Education Labour Relations Council (ELRC) [1] states that the IQMS is intended to integrate the existing quality management programmes in the education system. The existing programmes are the Developmental Appraisal System (DAS), Performance Measurement (PM), and Whole School Evaluation (WSE). Nel and Haasbroek [2] hold that effective training and development by the organisation is necessary to ensure that employees achieve the required level of competence. Information presented in this article focuses on the challenges faced by Development Support Groups (DSGs) in implementing the IQMS in Circuit 04 schools in the Mthatha Education District of the Eastern Cape Province, South Africa. In this regard, a qualitative research approach was used in this study to identify and investigate challenges faced by DSGs in implementing the IQMS in Circuit 04 schools. This research relied on oral interviews instead of numerical data and then analysed the spoken discourse [3], hence the use of a qualitative approach.

1.1. Background to the Study. According to Machingambi et al. [4], the central focus of performance management is the improvement of professional practice, motivating teachers and instilling a sense of accountability in teachers. The introduction of the Performance Management System (PMS) in African countries such as Zimbabwe and South Africa has been characterised by the concern for improved 
quality, a greater degree for accountability, and more efficiency, as well as a move to develop teachers as professionals. In this way, the performance management system functions as a form of in-service professional development and as a means of identifying the weaknesses and needs of teachers for improvement in the quality of teaching and learning [4].

The election of a democratic government in 1994 saw a major change in the racially segmented South African education system with it becoming the central focus of transformation [5]. The first move was the induction and founding of a legitimate, nonracial, and democratic Ministry of Education that opened the way for the enactment of various policy documents and acts. Thereafter, teacher development became one of the major focuses for transformation [6].

The Department of Education introduced the Developmental Appraisal System (DAS) aimed at facilitating personal and professional development. By 2000, however, it emerged that the DAS did not focus on the holistic functioning of the school. As a result of the dysfunctionality of the DAS and failure by schools to implement PM, the IQMS was introduced in 2003 and was scheduled to be implemented in all public schools in 2004. IQMS components comprised the DAS, Performance Management (PM), and Whole School Evaluation (WSE). A study conducted by Masetla [7] on examining challenges in the implementation of performance appraisal (PA) on educators in the Shiluvana Circuit of the Mopani District, South Africa, revealed severe shortcomings in the use of the Integrated Quality Management System (IQMS) for school-based performance management. The study indicated that the IQMS was insufficient, that its application was ineffective, and that it did not support school-based performance management. It was mere a compliance system and did not allow schools' stakeholders the freedom to take part in designing their own strategy for their school's development. This is further supported by a study conducted by Booyse [8] which revealed severe shortcomings in the use of the Integrated Quality Management System (IQMS) for school-based performance management.

A study conducted by Hynek et al. [9] in Norway on the improvement of interprofessional collaboration in Norwegian primary schools revealed that one of the factors that could promote or hinder interprofessional collaboration was lack of time or resources to practice collaboration across professionals from different agencies. This means that when there are no human resources to monitor and evaluate IQMS programmes in schools, this will have a negative effect on the implementation and performance of learners in schools; thus, the intended outcome of a good strategy will not be achieved, and it will be of no benefit if there is no effective evaluation and no monitoring of its implementation $[8,10]$. In the same vein, Oguguo [11] maintained that when people are monitored and constrained in executing a duty, they perform better and vice versa; therefore, for IQMS to function effectively in schools, there is the need for effective monitoring and evaluation.
1.2. Statement of the Problem. Based on one of the researcher's experience as an educator working for 19 years in one of the senior primary schools in the Mthatha Education District, teachers' inadequate experience, skills, and knowledge of the various subject areas were noted. In addition, poor performance in the various schools was being recorded, hence the current study. She also noted the inadequate support, training, and development in the form of appraisal of teachers in the schools. This resulted in teachers being dissatisfied when the DSGs attempted to implement the IQMS. The researcher, thus, was interested in conducting this study investigating challenges faced by DSGs in the implementation of the Integrated Quality Management System (IQMS) in Circuit 04 primary schools in the Mthatha Education District. The justification for this investigation is that the actual performance of teachers in schools is critical to the success of education in South Africa, ensuring improved levels of education. This study was also worth investigating because the implementation of the IQMS in schools is aimed at determining the competence of teachers and assessing their strengths and areas for further development.

1.3. Research Question. The research question guiding this investigation is What challenges are faced by DSGs in the implementation of the Integrated Quality Management System (IQMS) in Circuit 04 primary schools in the Mthatha Education District?

1.3.1. Theoretical Literature Review Framework. The theoretical framework underpinning this study is the Integrated Quality Management System (IQMS) framework, which incorporates three systems, namely, Developmental Appraisal (DA), Performance Measurement (PM), and Whole School Evaluation (WSE) developed and agreed upon in 2003 as part of a collective agreement between the Department of Education, as an employer, and the teacher educator unions [7]. The tenets of the IQMS are underpinned by the purpose of quality management systems which are to determine competence, to assess strengths and areas for further development, to ensure continued growth, to promote accountability, and to monitor the overall effectiveness of an institution [8].

The use of this framework in the current study underpins the implementation of the IQMS to ensure effective evaluation of teachers following the collapse of the inspectorate system, as indicated by Mosoge and Pilane [9]. It was, thus, an attempt to offer guidance and to ensure the delivery of an effective education system in the country. As posited by structural-functionalist theory, if any part of the school as a system does not function well, for example, teacher competency, content knowledge, and classroom effectiveness, then the whole school as a system is affected and this can then result in a poor culture of teaching and learning in the school. The use of this framework serves as a benchmark to ensure the delivery of quality education.

The system of the IQMS can be explained on the basis of the structural-functionalist theory which seeks to describe 
how order, quality, and stability are achieved in an organisation such as at a school. Structural-functionalism is a framework based on the view that society is a complex system whose parts work together to promote solidarity and stability $[9,10]$. A school may also be seen in this light as it is composed of different parts that work together to attain the school's goals. The structural-functionalists, therefore, see an organisation, such as a school, as consisting of several parts that work in tandem to achieve certain defined goals. Although the different parts are organised to fulfill different needs, they are dependent on one another. The use of the Integrated Quality Management System (IQMS) framework in this study, therefore, incorporates structural-functionalism ideologies to ensure that the IQMS is implemented effectively through certain structures in the school that work together to evaluate individuals as well as the school as a whole [9].

1.4. Purpose of the Study. The purpose of this study as already stated was to investigate the challenges faced by Development Support Groups (DSGs) in implementing the Integrated Quality Management System (IQMS) in four primary schools of Circuit 04 of the Mthatha Education District of the Eastern Cape Province, South Africa, and it suggests relevant remedies to assist them overcome those challenges in order to improve learner performance.

1.4.1. Perceptions of IQMS Implementation in Schools. Machingambi et al. [4] state that the perceptions of teachers towards performance and assessment in schools includes aspects such as school heads' abuse of the performance management system, schools not conducting staff development programmes with their staff, no meaningful reward for those teachers who perform well, teachers' lack of training despite a performance management system, and the shortage of resources and materials in schools. Even though the IQMS (ELRC) was introduced in 2003 in South Africa as a measure to hold schools accountable [9], it is not without challenges; the major challenge includes the integration of disparate appraisal activities, such as formative and summative evaluation, into one instrument. In addition, the linking of the IQMS with pay progression has distorted its developmental purpose and value [12]. This means that performance management has not received due attention, particularly as the implementation of the IQMS has met with teacher resistance as this accountability system is viewed as a "tough-on-schools" policy aimed at apportioning blame on teachers for the ills of education [9].

In a study, Donaldson [10] reports on the analyses of summative evaluation ratings of teachers at Five Town CSD and Maine School Administrative District in Alexandria, United States of America (USA), which indicates that the vast majority of teachers were rated above average. Although it is possible that all teachers were above average in some schools, there is generally more variation in teacher effectiveness within schools than between them; thus, any school, low performing or high performing and wealthy suburban or underresourced urban, is likely to employ more underperforming teachers than its evaluation ratings suggest. In fact, both principals and teachers believe that teachers are less effective than ratings indicate.

Inflated ratings of teachers reflect problems that limit the extent to which evaluation can improve instruction and achievement [10]. These include the following:

(i) Poor evaluation instruments: systems have tended to emphasise what can be measured, but not necessarily what matters; thus, evaluation instruments have traditionally required evaluators to look for things that they can easily check off (such as the neatness of bulletin boards) but may not indicate high-quality instruction.

(ii) Limited district guidance: districts typically give little direction regarding what evaluators should look for. Instead of providing guidelines and rubrics about the substance of evaluations, districts are more likely to set out time lines and explain processes [11].

(iii) Lack of evaluator time: evaluators, usually school administrators, report having insufficient time to conduct thorough and accurate evaluations. As the reporting requirements for schools have increased, evaluators' time has become even scarcer.

(iv) Lack of evaluator skill: evaluators often lack specific knowledge about the content areas in which they evaluate teachers, especially at the secondary level. Moreover, professional development for evaluators is neither frequent nor comprehensive.

(v) Lack of evaluator will: principals are not always held accountable for conducting rigorous evaluations. A 'culture of nice' pervades schools, suppressing critical feedback and encouraging principals to rate all teachers above average.

(vi) Absence of high-quality feedback for teachers: even though teachers express a strong desire for more concrete, detailed feedback, evaluators generally do not provide it after their observations.

(vii) Few consequences attached to evaluation: because there is little variation in teachers' summative evaluation ratings, teachers who teach exceptionally well cannot be identified or rewarded. At the same time, it is difficult to identify and remediate or, if needed, dismiss those who struggle [10].

In the Northern U.S. Charted Management Organisation, teacher evaluation is considered a more powerful tool for instructional improvement. One charter management organisation in the northern United States, a successful network of 15 urban schools serving high percentages of low-income and minority children, has improved instruction by deemphasising formal summative evaluations and focusing instead on ongoing informal evaluation and feedback [13]. Eric and John [14] believe teacher evaluation improves teaching, with their study revealing that the effectiveness of individual teachers improved during the school year in which they were evaluated. Specifically, the 
average teacher's students scored 0.05 standard deviations higher on end-of-year mathematics tests during the evaluation year than in previous years, although this result is not consistently statistically significant across different specifications; however, the average teacher's students scored 0.11 standard deviations higher in years after the teacher had undergone an evaluation compared to how his/her students scored in the years before the evaluation.

Researchers found that teachers in Chicago had positive perceptions of the overall teacher evaluation process, especially when they valued the leadership of their principals and when principal-teacher trust was rated as being high. However, they found the evaluation process contributed to teacher stress and decreased satisfaction in the teaching profession. They also learned that "teachers had negative perceptions about the inclusion of student growth metrics" [15].

\subsubsection{Support of Primary School Teachers in the IQMS} Process. The question then arises How are effective teachers cultivated and supported in schools for the benefit of all children? School Development Teams (SDTs) should focus the collective efforts of all school personnel on the primary goal of developing a culture of improved teaching and learning, hence the birth of the IQMS. The literature has shown that the best way to achieve quality in the public service sector is through implementation of quality management systems to monitor the progress of the work conducted by the individuals in service [16]. Thus, a quality management system must be driven by clearly defined goals and strategic plans which must be managed by competent and reliable people to ensure its efficacy on implementation in order to achieve a better outcome for any organisation. In this case, How can the IQMS help teachers achieve better learner performance? The performance of teachers is, after all, the foundation for achieving the goal of increased learner achievement. Evaluation of programmes and practices is essential to ongoing effort to improve any profession. Evaluation does not stand alone but is a part of the educational process [17]. Leggat [12], on the issue of barriers to teacher support, explains that, for performance management to reach 'lofty heights,' school managers need to recognise that their role has changed from performance evaluation to the development of staff.

Maphutha [18] asserts that professional development is overlooked when formative and summative evaluations are applied together because teachers tend to focus on summative evaluation which, in many cases, is linked to salary progression. Performance management, aimed at developing teachers, is overshadowed in favour of summative evaluation. Teachers are, thus, tempted to focus on satisfying the demands of summative evaluation in order to gain salary progression, grade progression, and affirmation of appointments. Donaldson and Peske [13] argue that 'feedback is a gift,' particularly as a key part of professional development focuses on training teachers and leaders to engage in difficult conversations, which sometimes occur during evaluation debriefing. Staying on one side of the net and not overstepping the mark by making negative claims help to depersonalise disagreement. Principals, during the process, should deliberately offer critical feedback on demonstration lessons to see how teachers handle constructive criticism and use it to inform their development. Evaluators receive training on how to deliver feedback in such a way that their suggestions are implemented and by learning to give concrete and specific feedback to which teachers can immediately respond. Evaluation and coaching sessions deliberately focus on one or two major issues on which a teacher needs to work, and these tend to be anchored in student data, often the organisation's benchmark assessments. However, this narrow focus does not necessarily help teachers make the relevant and necessary changes to their teaching practice [13].

Callahan and Sadeghi [19] explain that teacher evaluation systems, ideally, should foster improvement in both professional development opportunities and teaching practices. However, in the real world, theory often fails to inform practice. The theory of action behind supervision and evaluation is flawed, and the conventional process rarely changes what teachers do in the classrooms. Inadequate assessments are all too common, which means poor performance is not addressed, teaching excellence is not acknowledged, new teachers do not receive the feedback they need, and professional development is not aligned with areas of need.

As stated previously, teacher evaluations, as currently conducted, fall short. Overall, teacher observations are brief and infrequent and they fail to differentiate amongst teachers. Proponents of education reform, therefore, rightfully argue that the current teacher evaluation systems are inadequate [20]. Often, these evaluations involve a short "walk-through" visit by the principal or other administrator. The evaluators rely on a rubric that serves as a checklist of what they observe in the classroom. These rubrics tend to focus on trivial items that can be measured and have little to do with learning outcomes, school improvement efforts, or professional development opportunities [21].

Weissberg et al. [22], when conducting research on the rigour of teacher evaluations of 12 school districts in four different states in the USA, found that less than one percent of surveyed teachers received a negative rating on their most recent evaluations. Multiple factors, often working in tandem, produce this effect. External constraints decrease evaluators' inclination to evaluate rigorously based on vague district standards, poor evaluation instruments, overly restrictive collective bargaining agreements, and a lack of time. These all contribute to this problem. Internal constraints, including a school culture that discourages negative ratings and a district culture that offers little oversight and few incentives, also ultimately contribute to the inflated teacher ratings.

The American Federation for Teachers [23] and the National Education Association [24] have acknowledged the need to reform teacher evaluation systems as the existing systems in the USA are inadequate. Both associations highlight the importance of using multiple measures to assess teacher effectiveness, such as classroom observations 
and district-wide assessments, as well as additional opportunities for feedback. They also emphasise the importance of targeted professional development. Research demonstrates that professional development opportunities, when properly designed and implemented, have the potential to enhance classroom practices and ultimately improve student learning outcomes. The key is providing professional development that is timely, relevant, and effectively delivered. Professional development that is provided in an effective way can have a measurable impact on school improvement and student achievement [19].

According to the Parliamentary Monitoring Group [17], for more than two decades, teachers in South Africa, especially in black schools, were not subjected to any kind of evaluation. It is very possible that this situation has contributed towards the unsatisfactory results seen in learner achievement. The classroom teacher is the central figure in the process of educating children, and therefore, a performance-based teacher evaluation system is critical in improving teaching and learning. The requirements of public education have changed substantially in the last ten years and schools, as well as education managers at all levels of the system being required to respond to the heightened expectations of parents and society. The key role that teacher professional development plays is, therefore, a way of improving the quality of teaching and classroom practices. However, while the Performance Management System (PMS) offers much hope for how to improve educational quality, very few schools have been able to really implement and effectively utilise its potential.

The New Zealand Educational Institute [25] claims that teachers and support staff performances are managed to provide feedback and identify training needs so that their knowledge and experience is enhanced and developed. In this way, appraisal of teachers has a direct benefit for the learning experience of learners, with appraisal of support staff enhancing their contribution to teams in schools. Callahan and Sadeghi [19] reflect that, in theory, a teacher evaluation system should measure a teacher's strengths and weaknesses through an accurate and consistent process that provides timely and useful feedback. The evaluation and feedback should inform instruction and professional development opportunities to improve classroom instruction and educational outcomes [26].

Darling-Hammond [20] contends that decades of research have shown that there is a significant relationship between teacher effectiveness and achievement. The "effects of well-prepared teachers on student achievement can be stronger than the influences of student background factors, such as poverty, language background, and minority status. Yet, existing teacher evaluation systems often illustrate no relationship between teacher effectiveness and student outcomes" [20].

From the researchers' points of view, it can be concluded that the IQMS, if correctly and effectively implemented by all parties, could improve the teaching practice and the academic performance of learners, thus ensuring a culture of teaching and learning, as well as effected school management and governance practices in schools.
1.5. Research Methodology and Design. A qualitative approach was used in this study guided by a case study research design which involved a case of four selected primary schools located in the Mthatha Education District of the Eastern Cape, South Africa.

1.6. Population and Sampling. The population of this study comprised teachers of senior primary schools of Circuit 04 in the Mthatha Education District. A convenience sampling technique was used to select two DSGs and two teachers, comprising four representatives from each of the four senior primary schools, resulting in sixteen (16) participants in the sample. The sample comprised DSGs and teachers who were easily and conveniently available to the researcher in Circuit 04 of the Mthatha Education District. These participants were willing to participate in this study and understood what was expected of them and were well informed about this study.

1.7. Instrument. The strategy used to collect the data depends on the research question, and in this study, face-toface individual in-depth interviews were conducted to collect data from the sampled participants. The interviews took place in one particular school where the participants converged under the instruction of the researcher at an appropriate time convenient to the participants. An interview schedule was prepared to guide the interview process and ensure that the discussion did not deviate from the purpose of the study. The participants were interviewed individually in a particular office isolated from where other participants waited for their scheduled interviews in order not to compromise the trustworthiness of the interviews and the study as a whole. The duration for the interviews per participant was approximately 30 minutes.

\section{Data Analysis and Presentation}

Data, obtained through face-to-face interviews, with 16 sampled participants, were studied several times to identify repeated themes. Data were also repeatedly scrutinised, synthesised, and transcribed verbatim. The goal of the researcher in the data-analysis stage was to create descriptive, multidimensional categories for the analysis of the data through the process of coding. The researcher initially allocated codes to chunks of the raw data. These codes, as meaningful segments, were then examined in a holistic fashion. This means that the collected data were thematically analysed and related categories were grouped in order to facilitate the development of logical and meaningful themes and categories. The next stage was to reexamine the themes and categories that had emerged and then interpret and synthesise these into a general conclusion or understanding. White [27] avers that qualitative data analyses involve becoming familiar with the data in depth to provide detailed descriptions of the situation, participants, and activities by categorising and coding pieces of data and then grouping these into themes and interpreting and synthesising the 
organised data to make it understandable, so that findings are derived from emerging themes [28].

2.1. Data Presentation. The analysis of the responses to each question, as well as the excerpts and examples from participants, is presented in the following sections.

\subsection{Analysis of Responses from Teachers and DSGs.} Question 1: To what extent has the IQMS been implemented in this school?

Participants responded to this question by acknowledging that as teachers, they knew the IQMS was ongoing and implemented every year, with staff meeting to suggest appropriate times and dates. During an IQMS workshop, DSGs are elected according to expertise and learning area. On the specific dates, the allocated DSGs accompany the teachers to the class for observation of their lessons. Participants reported that the IQMS began with teachers completing a special self-evaluation instrument and then DSGs rated and scored teachers on their performances, irrespective of whether they performed well or not. Participants also claimed that, before and during any IQMS exercise, two structures for School Development Teams (SDTs) and DSGs were created during summative evaluation. The following excerpts confirm these responses:

Participant A (DSG): as we are doing the IQMS at my school, we know that it is continuous. We sit down and come up with dates. Each and every one is given a date. Your DSG goes with you to the class where you are observed.

Participant C (teacher): in my school, the IQMS is done by calling all teachers to a workshop at school. At the same time, we elect the DSGs according to our expertise of our learning area.

Question 2: In what way has the IQMS assisted in achieving a degree of teacher accountability in schools? Explain.

The participants reported that accountability, as a result of the IQMS process, had increased with teachers' and learners' performance showing a marked improvement. The implementation of the IQMS meant that teachers were very aware that they were being monitored. This ensured that they were taking full responsibility for their teaching, preparing their lessons and ensuring that they were in class teaching. As a result, higher performance and greater accountability was reported in the schools. The examples below support these assertions:

Participant C (DSG): I can say there is accountability done by the IQMS because learners' and teachers' performance has increased

Participant D (teacher): teacher accountability has been created by the IQMS because teachers know that they are monitored by the DSG
Question 3: To what extent has IQMS implementation ensured greater efficiency as well as a move to teacher development and professionalism in the school?

The participants reported that the results from the IQMS revealed gaps, deficits, and needs which needed to be addressed. This information was reported in the School Improvement Plan (SIP) and informed training and development of staff by the SDTs at schools. Teachers received training as the result of the IQMS which shows that the IQMS was being implemented with greater efficiency, thus resulting in professional development. However, it was also mentioned that it took some time for training and development of teachers to be done, based on the goals of the IQMS. This could occur with participation in in-service training workshops and in the IQMS programmes which assist teachers in upgrading their qualifications in their specific subjects. The following excerpts confirm the views:

Participant H (DSG): what I can say is that teachers are sent to training from the information which comes as a School Improvement Plan (SIP) done by the SDT at school.

Teacher F (teacher): not all of us have been trained by the IQMS. I can say it takes longer time to train after they have a certain group.

Participants claimed that IQMS implementation ensured teacher development and professionalism led by the SDT and DSGs. Lesson observation assisted teachers in identifying weak areas, and the subsequent training helped to narrow or close the gaps. Based on the result of the IQMS, teachers attended workshops conducted by subject advisors to assist them in improving their knowledge of the learning areas and bridging content gaps. Workshops allowed all teachers of the same phase to attend so that they were equipped with the requisite content and pedagogical knowledge. The responses below confirm these claims:

Participant E (DSG): IQMS implementation has ensured teacher development and professionalism by the SDT and DSG roles

Participant C (teacher): lesson observation is the one which shows a teacher's lacking area, and that teacher is taken to training

Question 4: What are your perceptions with regards to how principals manage the IQMS?

The study revealed that the way the IQMS was being managed by the principals was not encouraging even though they were part of the team and structure engaged to manage the IQMS. The participants indicated that principals seemed to lack knowledge about the IQMS, thus resulting in ineffective or no management plans with regard to the IQMS. This meant that school principals found it difficult to implement the IQMS, and in some schools, the IQMS was not being implemented. This is what some of the participants had to say: 
Participant F (DSG): school managers do not understand the IQMS well, so they find it difficult to manage the IQMS.

Participant G (teacher): school managers rarely manage the IQMS because you will see that there are no management plans drawn in your school. You will only hear about the plan when you are in workshops with other teachers.

The participants indicated that the IQMS was a process consisting of a number of steps whereby teachers evaluated themselves using the same instrument that is used for both Developmental Appraisal (DA) and Performance Measurement $(\mathrm{PM})$. This process enables the teachers to become familiar with the instrument and familiarise themselves with the performance standards and the criteria (what they are expected to do), as well as the levels of performance (how well they are expected to perform) in order to meet at least the minimum Integrated Quality Management System (IQMS) standards. Thus, after a preevaluation discussion with the teachers, the DSGs observe the teachers in the classroom and assess them using the same instruments. Thereafter, a further discussion is entered into in order to develop a Personal Growth Plan (PGP). The findings revealed that participants' perceptions were that school principals were part of the team and structure required to manage the IQMS; the principal together with the SDT drew up the management plan so that the teachers were aware of the activities planned for each month. Some of the excerpts to support these perceptions are as follows:

Participant C (teacher): my principal, with the SDT, draws the management plan so that the teachers might see activities done on that month

It was, however, also perceived by some participants that the school principals were not fully involved in carrying out IQMS activities as noted below.

Participant D (DSG): I can say even though they are part of the SDT, principals just depend on the structure to manage the IQMS

The principal has the overall responsibility to ensure that the IQMS is implemented uniformly and effectively, and this begins with ensuring that every teacher is provided with a copy of the IQMS document and other relevant IQMS documentation. Together with SDT members, the principal is responsible for advocacy and the training of all teachers and should give them the opportunity to clarify areas of concern. The principal, in collaboration with the SDT, monitors the process throughout the year, is responsible for internal moderation of evaluation results in order to ensure fairness and consistency, and ensures that all documentation sent to the district office is correct and delivered in time.

Question 5: What meaningful rewards are offered to teachers who have performed well in an IQMS process?

It was claimed by the participants that the results of the DA and PM were submitted to the IQMS office in the district. It seems that teachers are eligible for a $1 \%$ rise in salary, a percentage agreed upon by the government, whereby every teacher is rewarded based on the results of the IQMS. Rewards include issuing of certificates and a $1 \%$ salary increment from the government. The following responses support these claims:

Participant G (DSG): with the scores submitted to the IQMS section in the district, teachers are able to get a $1 \%$ offer from education dept. This is the only reward I can talk about.

Participant D (teacher): yes, there are awards where teachers are awarded with certificates in my school and $1 \%$ from the government.

Question 6: Is the integration of disparate appraisal activities (formative and summative evaluation) into one instrument a challenge?

It was claimed by participants that the integration of disparate appraisal activities (formative and summative evaluation) into one instrument is a challenge because it brings about confusion among teachers and sometimes delays their work since summative evaluation is done at the end of the year whereas appraisal activities and formative evaluation are done throughout the year. The participants also indicated that, in many cases, there was a lack of support from the SDTs. This delayed their work resulted in resistance to the process. This confirms a study conducted by Hynek et al. [9] which revealed that lack of time or resources to engage in collaboration amongst professionals from different agencies is one of the factors that can promote or hinder interprofessional collaboration, and therefore, human resources are considered important for monitoring and evaluating IQMS programmes in schools in order to eradicate any negative effect on the implementation and performance of learners in schools. In some cases where little preparation is given, teachers do not want to be evaluated at all since they have no idea as to what is to be evaluated. It was evident that teachers really faced challenges when disparate appraisal activities (formative and summative evaluation) were integrated into one instrument and teachers were resistant to the process. The following examples support the abovementioned claims:

Participant B (DSG): to integrate appraisal activities, formative and summative evaluation into one instrument is a big challenge because we lack support from the SDT

Participant C (teacher): some teachers don't want to be evaluated at all since there's no clarity as to what is to be evaluated and the procedure to be followed or how to evaluate since we receive no support from the SDTSDT; even if the date has been set, they don't honour at all

Question 7: What can you say about the adequacy of assistance provided by the school management for teachers to prepare for the IQMS process?

Participants reported that workshops were conducted to prepare teachers for the IQMS process by compiling a list of DSGs elected for the specific subject and drawing up a monthly management plan for teachers to ensure that they were aware of the activities for the month. In addition, a 
record book was allocated to each teacher in which the DSG recorded observations and other information about the teacher. The following excerpts confirm these preparations:

Participant E (teacher): the management provides adequate support to teachers towards/during IQMS implementation by means of workshops for teachers

Some of the participants claimed that the school management did not prepare the teachers for the IQMS process. The following excerpts confirm these claims:

Participant B (teacher): By this time, the school management is expected to make us aware of the IQMS, but they don't prepare us at all for the IQMS

Participant $\mathbf{H}$ (teacher): The assistance is not enough that is provided by the school management to teachers to prepare them towards the IQMS process in the school

In order for teachers to successfully participate in the IQMS, they need to be prepared to undertake self-evaluation of their performance, identify their personal support group, develop a Personal Growth Plan (PGP), and finalise it together with the DSG. In addition, they should co-operate with the DSG, attend programmes in terms of areas identified for development, and engage in feedback and discussion.

Question 8: To what extent has the management gone beyond being teacher appraisers to teacher developers?

Participants acknowledged that development programmes for teachers had been put in place in some of the schools; however, it was felt that immediate seniors such as Heads of Department (HODs) needed to be fully equipped with the necessary knowledge and skills so as to develop teachers' skills based on the results of the appraisal.

Participant F (teacher): the management has a duty to develop the immediate seniors, that is, the HOD, so that they can develop teachers at large.

This is particularly important when ensuring continuous professional development with the implementation of a changing curriculum.

Participant B (DSG): the management has a role of developing all teachers at school. They now change from appraisers and tend to develop teachers.

Teachers need to receive the necessary support and mentoring from the member(s) of the DSG so as to improve their practice in both subject content and pedagogical content knowledge. The mentoring must be ongoing in terms of the responsibilities of the immediate senior, and peer mentoring and support should also be ongoing, though there are likely to be less formal and less-structured interactions.

Question 9: How true is the claim that teachers are not supported by the management in providing them with feedback when identifying their training needs after appraisals?

Participants reported that teachers were supported by the management who provided them with feedback after appraisals and assisted teachers in identifying their training needs. Teachers reported that feedback informed their Personal Growth Plan (PGP) which was developed in consultation with their DSGs. The PGP, in turn, was used to inform the School Improvement Plan (SIP). The SIP then assisted in identifying areas in which teachers needed training in order to ensure improved teaching and learning. Teachers who had been identified as needing training because they were un- or underqualified or needed reskilling in order to teach a new subject were given relevant feedback and supported by training. The examples below support these assertions and claims:

Participant A (DSG): this is not true in my school because from the SIP done by the SDT, teachers have been trained in those areas they need to be done.

Participant C (teacher): feedback is done by the management in schools. Teachers who have been identified as in need of training are taken into consideration.

The DSGs must discuss their evaluations with the teachers and then provide feedback which should focus on performance and not personality, observations and not assumptions, objectivity and not subjectivity, the specific and concrete and not the general and the abstract, the sharing of information and not simply giving of instructions, and attention to the individual's needs and requests. This feedback, thus, informs the teacher's Personal Growth Plan (PGP).

Question 10: How does pay progression distort the teacher development purpose of the IQMS and, consequently, affect the performance of learners at schools?

As previously indicated, the IQMS was developed to determine competence, to assess strengths and areas for development, to identify specific needs of teachers, to provide support for continued growth, to promote accountability, to monitor an institution's overall effectiveness, and to evaluate an educator's performance. Some participants felt that pay progression motivated teachers to work harder and produce good results. This positive attitude to the teaching and learning process helped learners to perform well because teachers felt that they were being rewarded through pay progression which encouraged them. The following examples support the abovementioned commentary:

Participant C (DSG): the pay progression is the one that makes the learners to perform well because teachers work hard in order to get the money

Participant G (teacher): the pay progression encourages us as teachers to work hard and produce good results

Most participants reported that pay progression distorted the teacher development purpose of the IQMS which consequently affected the performance of learners. It seems that, in many cases, teachers performed well but mainly because they wanted to be awarded the pay progression; some only worked well during the appraisal process and not consistently. This means most teachers viewed the process of the IQMS merely as a means for a salary increase and neglected the other aspect of teaching and learning which is the main focus of the job description. If this is the case, it 
could contribute to the poor performance of learners due to teacher incompetence and resistance to continuous professional development. The excerpts below confirm these statements:

Participant F (DSG): the pay progression can distort teacher development purpose of the IQMS and, consequently, the performance of learners at school in that teachers who have not been developed could not perform well and so cause learners to perform badly.

Participant D (teacher): teachers only work well when it is the time to get pay progression. During the year, they will relax and only focus on summative evaluation because they know it comes with money.

Question 11: To what extent does teacher resistance to the implementation of the IQMS at schools contribute to poor performance of learners in schools?

Participants clearly stated that teacher resistance to the implementation of the IQMS had contributed to the poor performance of learners because some teachers did not want to change their traditional ways of teaching. Through the IQMS, a teacher becomes aware of his/her weaknesses, but if teachers resist participating in the IQMS, they do not have the opportunity to undergo professional development offered by the DSG and which could improve their knowledge and skills and, thus, have a positive effect on learner performance. The following responses confirmed that mentioned above:

Participant C (DSG): teacher resistance to the implementation of the IQMS at school contribute to poor performance of learners because the IQMS is about development, support, and monitoring and that creates teacher competency in order for her to perform good in class and make good results to the learner, but those who refused to be appraised will not be developed

Participant A (teacher): yes, it can contribute because the DSG's role is to work hand-in-hand with teachers by supporting and monitoring them, but some teachers do not like that

If schools wish to improve and provide quality teaching for their learners, teachers need to develop themselves professionally in their knowledge, skills, values, and attitudes. This means that there is a need to be self-directed, with teachers displaying willingness to learn, acquire, and develop new skills and knowledge. For professional development to be effective, motivation should be intrinsic rather than extrinsic.

Question 12: How true is it that teachers are tempted to focus on satisfying the demands of summative evaluation rather than formative evaluation in order to gain salary progression, grade progression, and affirmation of appointments?

Even though the purpose of the IQMS is Performance Measurement (PM) where individual teachers' performance is evaluated for salary progression, grade progression, affirmation of appointments, and rewards and incentives, teachers need to bear in mind that the other purpose of the
IQMS is Developmental Appraisal (DA) where individual teachers are appraised in a transparent manner with a view to determining areas of strength and weakness and to draw up programmes for individual development.

Participants agreed that teachers were tempted to focus on satisfying the demands of summative evaluation rather than formative evaluation in order to gain salary progression, grade progression, and affirmation of appointments. Participants said it was not easy to get appointed or promoted, so the summative evaluation did offer a positive outcome in that teachers were offered an increase in salary.

Participant G (DSG): teachers are tempted to focus on satisfying the demands of summative evaluation than formative evaluation to gain salary progression, grade progression, and affirmation of appointments and so affect the performance of the learners

Participant B (teacher): yes, it is true because as we know that it is not easy to get promoted in our department, at least summative comes with certain percentage that increases our salary

Question 13: How does a lack of teacher evaluation contribute to learners' poor performance at school?

Participants responded to this question by stating that lack of teacher evaluation tended to have a negative impact on learners' performance at schools. Participants felt that if teachers were not evaluated, weaknesses and strengths could not be identified. The excerpts below support these responses:

Participant D (DSG): no matter how good you are, you need to develop because of the changing curriculum so as to be an expert. If you lack evaluation, you will not know the changes offered by the Department of Education.

Participant A (teacher): what I can say is that if I have not been evaluated, no one will know my weaknesses and strengths, I will not develop, and so, contribute to poor performance at school.

The teachers realised that if they did not participate in the IQMS process, they would not have the opportunity to undergo professional development or be assisted with areas identified as weaknesses which could contribute to poor teaching and learning, thus resulting in low learner performance. Because of the changes in the curriculum, evaluation allows for development in order to ensure that the curriculum is effectively implemented and, thus, there is school improvement and enhanced learner performance.

\section{Discussion of Findings}

As previously discussed, the central focus of performance management is the improvement of professional practice, motivating teachers, and instilling a sense of accountability in teachers [4]. In South Africa, the ELRC [1] states that the IQMS is intended to integrate the existing programmes on quality management in education which include the Developmental Appraisal System (DAS), Performance Measurement (PM), and Whole School Evaluation (WSE). Nel 
and Haasbroek [2] hold that effective training and development by the organisation is necessary to ensure that employees achieve the required level of competence which in turn assists in the development of a culture of teaching and learning and ensures greater learner achievement. The discussion of findings takes into consideration the themes that emerged during analysis and are presented below.

Theme 1. Perceptions of DSG members regarding IQMS implementation in primary schools.

The study revealed that school principals were part of the team and structure required to implement and manage the IQMS in their schools; however, management plans with regards to the IQMS were not often put in place in some of the schools. This resulted in school principals finding it difficult to ensure that the IQMS was effectively implemented. A participating DSG member said I can say even though they are part of the SDT, principals just depend on the structure to manage the IQMS. In contrast, it seemed that some principals in collaboration with the SDT developed plans for the IQMS. A participating teacher concurred when he said My principal with the SDT draws the management plan so that the teachers might see activities done on that month.

The study, thus, revealed that some school principals were not fully involved in initiating IQMS activities as they lacked knowledge about the IQMS, resulting in no IQMS management plans and a difficulty in ensuring that the IQMS was effectively implemented. This finding aligns with the work of Machingambi et al. [4] which showed that the perceptions of teachers regarding performance and assessment in schools indicate that school heads abuse the performance management system, are not adequately trained to implement the IQMS, and consequently, staff development programmes are not implemented in many of the schools. This results in poor performance of some teachers which has a negative effect on learners' performance in some schools.

The study also revealed the extent to which the IQMS had been implemented in the sampled schools. The findings indicated that, in schools where the IQMS had been implemented, the process began with teachers attending a workshop where they selected the DSGs according to expertise or learning areas. A teacher had this to say: In my school, the IQMS is done by calling all teachers to a workshop at school. At the same time, we as teachers elect the DSGs according to our expertise of our learning area. The IQMS was ongoing and carried out annually with all teachers being given dates for observation by the selected DSGs who observed certain lessons. In addition, the IQMS involved DSGs rating and scoring teachers on their performances. During the IQMS exercise, two structures involving SDTs and DSGs were created for summative evaluation. The following responses came from a DSG member: As we are doing the IQMS at my school, we know that it is continuous, so we sit down and come up with dates. Each and every one is given a date. Your DSG goes with you to the class where you are observed.

This finding further revealed that the IQMS had achieved a degree of teacher accountability in schools. The findings reveal that teachers were being evaluated. This means there is greater accountability and both teachers' and learners' performance has improved. As teachers are being monitored throughout the school year, the findings revealed that, with the implementation of the IQMS, teachers were now more motivated, not only to just be in the classroom but also to inspire, motivate, encourage, and educate learners. In addition, their roles involve counseling, mentoring, and teaching learners how to use and apply acquired knowledge in their lives.

Teachers impact their learners on different levels and inspire them to do more and be more. The assertions below were made by a DSG member: I can say there is accountability done by the IQMS because learners' and teachers' performance has increased. Another teacher said Teacher accountability has been created by the IQMS because teachers know that they are monitored by the DSG.

IQMS implementation has ensured greater efficiency as well as a move to teacher development and professionalism in many of the schools. The findings indicated that the results from the IQMS could be used to help train and develop staff, thus resulting in ongoing professional development programmes being implemented by the SDT and DSGs. Lesson observation in class has since helped teachers to develop, based on identified weak areas, gaps observed, and through the IQMS, teachers being workshopped by the subject advisors to help them acquire full knowledge of specific learning areas. It was also revealed that content gaps are dealt with at workshops which all teachers of a particular phase may attend so that they are able to acquire and develop the needed knowledge. Based on the information from the School Improvement Plan (SIP), some of the teachers underwent training. It was also revealed, however, that it often took a very long time for training and development of teachers to be carried out, based on the information from the IQMS, though sometimes teachers' skills were developed through short workshops at in-service training. The following views were expressed by a DSG member: What I can say is teachers are sent to training from the information which comes the School Improvement Plan (SIP) done by the SDT at school. Donaldson and Peske [13] confirm that as a part of IQMS implementation, teachers receive one-on-one and small-group coaching from administrators weekly or biweekly, as well as a mid-year summative evaluation. The coaching is differentiated according to the teachers' needs and aimed at developing teachers' skills over time. For the summative appraisal, evaluators and teachers completed the same six-page document. This appraisal form focuses on Aspects of Instruction, which covers such approaches as differentiation and checking for understanding [13]. However, while the performance management system offers great hope for how to improve educational quality, very few schools have been able to really implement and effectively utilise the potential of a PMS.

The findings also revealed that teachers were given meaningful rewards when performing well in the IQMS process. As indicated earlier, scores from the evaluation are submitted to the IQMS section in the district and based on this, teachers are awarded a $1 \%$ rise in salary and competent 
teachers are also awarded certificates. The following responses came from a DSG member: With the scores submitted to the IQMS section in the district, teachers are able to get a $1 \%$ offer from the education dept. Another teacher said Yes, there are awards where teachers are awarded with certificates in my school and a $1 \%$ rise from the government.

Theme 2. Barriers to adequate support of primary-school teachers in the IQMS process.

Hynek et al. [9] contend that, in South Africa, the IQMS was introduced as a measure to hold schools accountable. The findings revealed a number of challenges that primary teachers face during the IQMS process. The introduction of this system has not been without challenges, the majority of which has been the integration of disparate appraisal activities that consist of a formative and summative evaluation, into one instrument. This has been seen as a challenge because it brings about confusion among teachers and sometimes delays their work since summative evaluation is conducted at the end of the year whereas appraisal activities and formative evaluation are conducted throughout the year. The participants also indicated that, in many cases, there is lack of support from the SDTs which delays their work. The following claims were made by a DSG member: To integrate appraisal activities, formative and summative evaluation into one instrument is a big challenge because we lack support from the SDT. In some instances, there was resistance to the IQMS process with teachers not wanting to be evaluated at all, even if the date had been set, and other teachers finding excuses citing personal reasons.

The findings revealed that, in some schools, there was adequacy of assistance provided by the DSG and SDT to teachers to prepare them for the IQMS process. Workshops were held to prepare teachers for the IQMS process, DSGs were elected, and the monthly management plan were drawn so that teachers were aware of the activities scheduled for each academic month. Minutes were recorded for all teacher and staff members to be aware of the management plan. The following comments were made by a DSG member: The adequacy of assistance provided by the school management to teachers to prepare them towards the IQMS process in the school starts by drawing the lists of DSGs that were elected and then they draw the monthly management plan for teachers to be aware of the activities done for the month. Another teacher said By means of workshop at school, the school management assists teachers towards the IQMS.

However, the findings indicate that assistance provided by the school management in order to prepare teachers for the IQMS process was not adequate. The following claims were made by a teacher: By this time, the school management is expected to make us aware of the IQMS, but they do not prepare us at all for the IQMS. Another teacher agreed The assistance is not enough that is provided by the school management to teachers to prepare them towards the IQMS process in the school. Hynek et al. [9] are of the opinion that the implementation of the IQMS is always met with resistance from teachers who considered this accountability system to be a "tough-on-schools" policy aimed at apportioning blame on teachers for the ills of education.
The findings also revealed that the management in many cases failed to provide teachers with feedback and to identify their training needs after appraisals. However, in some schools, teachers who had been identified as having training needs were given feedback and subsequent training. The following assertions were made by a DSG member: This is not true in my school because from the SIP done by the SDT, teachers have been trained in those areas they need to be done. Another teacher said Feedback is done by the management in schools. Teachers who have been identified as in need of training are taken into consideration. Donaldson and Peske [13] underscore the importance of feedback which should be seen as a key part of professional development which focuses on critical feedback on observed lessons which informs further training and continuous professional development vital to the process of teaching and learning [13].

Theme 3. The extent to which inadequate teacher appraisal and evaluation impacts learners' performance.

The findings revealed that a lack of teacher evaluation has contributed to learners' poor performance at schools because if teachers are not evaluated, weaknesses and strengths are not identified and improved upon. A DSG member said this: What I can say is that if I have not been evaluated, no one will know my weaknesses and strengths, I will not develop, and so, contribute to poor performance at school. Teachers, therefore, will not have the opportunity to participate in continuous professional development and assisted in developing their knowledge and skills, particularly with curriculum changes and the introduction of new subject areas, which would contribute to enhanced learner performance at schools. This is reinforced by a response from by a DSG member: No matter good you are, you need to develop because of the changing curriculum so as to be an expert. If you lack evaluation, you will not know the changes offered by the department of education. The good performance of educators is the foundation for achieving the goal of increased learner achievement. Evaluation of programmes and practices is essential to any ongoing effort to improve any profession. Evaluation is not apart from but is a part of the educational process [17].

The findings revealed that teacher resistance to the implementation of the IQMS contributed significantly to poor performance of learners with some teachers not wanting to change and possibly being motivated to move away from traditional ways of teaching. Through the IQMS, a teacher is made aware of his/her weaknesses but if resistant, will not have the opportunity for professional development; this affects the learners. The following response came from a DSG: Teacher resistance to the implementation of the IQMS to school contributes to poor performance of learners because the IQMS is about develop, support, and monitor and that creates competency to the teacher in order for her to perform good in class and make good results to the learner, but those who refused to be appraised will not be developed. A teacher said the following: Yes, it can contribute because the DSGs' role is to work hand-in-hand with the teacher by supporting and monitoring him, but some teachers do not like that. 
The findings revealed that pay progression distorts the teacher development purpose of the IQMS and, consequently, the performance of learners at schools. In some cases, pay progression resulted in learners performing well because some teachers worked consistently hard in order to achieve a high score in the evaluation so as to obtain a pay rise. The following response came from a DSG member: No, the pay progression is the one that makes the learners to perform well because teachers work hard in order to get the money. Another teacher said The pay progression encourages us as teachers to work hard and produce good results. However, some teachers merely wanted the pay rise so they only worked well during the evaluation, but for the remainder of the year, they did not make an effort and only focused on summative evaluation because they knew it came with a financial gain. This is supported by the statements below by a DSG member: The pay progression can distort the teacher development purpose of the IQMS and, consequently, the performance of learners at school in that teachers who have not been developed could not perform well and so cause learners to perform badly. Another teacher agreed Teachers only work well when it is the time to get pay progression. During the year, they will relax and only focus on summative evaluation because they know it comes with money. This means that teachers were in fact tempted to focus on satisfying the demands of summative evaluation rather than formative evaluation in order to gain salary progression, grade progression, and affirmation of appointments. Teachers facing challenges regarding promotion rely on summative evaluation which offers the prospect of increases in salary, that being a reward of a $1 \%$ rise as well as the opportunity for promotion. A DSG member agreed Teachers are tempted to focus on satisfying the demands of summative evaluation than formative evaluation to gain salary progression, grade progression, and affirmation of appointments and so affect the performance of the learners. A teacher said Yes, it is true because as we know that it is not easy to get promoted in our department, so at least, summative comes with a certain percentage that increases our salary. According to Mosoge and Pilane [12], the linking of the IQMS with pay progression has distorted its developmental purpose and value. In this way, performance management has not received due attention in the implementation of the IQMS. Maphutha [18] asserts that professional development is neglected when formative and summative evaluations are applied together because teachers often focus on summative evaluation. Performance management, aimed at developing teachers, was being neglected in favour of summative evaluation. Teachers were tempted to focus on satisfying the demands of summative evaluation in order to gain salary progression, grade progression, and affirmation of appointments, according to this study.

\section{Significance of the Study}

The researchers envisage that the findings of this study can contribute to the knowledge of challenges faced by the DSGs in the implementation of the IQMS at Circuit 4 primary schools in the Mthatha Education District. The findings of this study can also be communicated to the department of education, teachers, and principals so as to understand the barriers to adequate support of primary-school teachers in the IQM process and the extent to which inadequate teacher appraisal and evaluation have an impact on learners' performance in the primary schools. Furthermore, the findings may assist the department of education to gain insights from the views and experiences of the SMT when implementing the IQMS in schools. The study also has the potential to provide feedback to the department of education on progress and challenges of implementing the IQMS in schools. Study participants may benefit from reflecting on and critically analysing their roles in IQMS implementation. It will certainly help educators to understand aspects which need to be developed and support required in IQMS implementation in schools.

\section{Limitations of the Study}

Since the study regarding the challenges faced by the DSGs in the implementation of the Integrated Quality Management System (IQMS) at Circuit 4 primary schools only in the Mthatha Education District is qualitative, it is evident that the findings cannot be generalized. This may prevent the department of education from ascertaining exactly what is happening in other circuits in the country and department of basic education may not give the necessary attention to the challenges faced by the DSGs in the implementation of the IQMS, hence no or limited solutions to the problem.

\section{Recommendations}

This study highlighted the challenges facing the DSGs in the implementation of the IQMS at Circuit 4 primary schools in the Mthatha Education District, South Africa. Taking the findings into account, the study recommends that formative and summative evaluation should not be integrated into one instrument due to difficulties involved. The department of education should co-operate with teacher unions to sensitise teachers to the need for the IQMS so as to mitigate their resistance and reluctance to be part of the IQMS processes in the schools. It is recommended that the department of education sees that all school principals are capacitated so as to take a leading role in the process of the IQMS, particularly with the drawing up and implementation thereof. The DSGs and SDTs should continuously monitor the process and provide teachers with adequate and timely feedback on their evaluation to ensure high academic performance of learners, while insisting that evaluation of teachers' work in the schools is conducted regularly since evaluation contributes to their development through constructive criticism, attending appropriate workshops, and being able to adapt to curriculum changes. The DSG and SDT ought to ensure accountability so that all teachers comply with the IQMS.

\section{Conclusions}

The study, investigating challenges faced by the development support group in implementing the integrated quality 
management system, found that the role of the principal in supporting the IQMS process is vital. People are often resistant to change, and the principal's influence is crucial in changing attitudes and managing the resistance to ensure that teachers' expectations are met in order for the development of a culture of teaching and learning to take place. In addition, the expertise and competency of the DSG and SDT in managing the process is vital to ensure its effectiveness and overcoming challenges through participation, empowerment, ownership, adaptability, and streamlining of the process of the IQMS.

\section{Data Availability}

The data used to support the findings of this study are available from the author upon reasonable request.

\section{Conflicts of Interest}

The authors declare no conflicts of interest.

\section{References}

[1] Education Labour Relations Council (ELRC), Collective Agreement Number 8 of 2003, Government Printers, Pretoria, South Africa, 2003.

[2] V. D. Nel and L. Haasbroek, Skills Development Act No.97 of 1998, Government Press, Pretoria, South Africa, 1998.

[3] K. Maree, First Steps in Research, Van Schaik Publishers, Pretoria, South Africa, Sixth edition, 2010.

[4] S. Machingambi, C. Maphosa, A. Ndofirepi, E. Mutekwe, and N. Wadesango, "Perceived challenges of implementing the performance management system in Zimbabwe," 2016, http:// www.krepublishers.com.

[5] R. Mestry, I. Hendricks, I. Hendricks, and T. Bisschoff, "Perceptions of teachers on the benefits of teacher development programmes in one province of South Africa," South African Journal of Education, vol. 29, no. 4, pp. 475-490, 2009.

[6] C. Manganye, Curriculum 2005. Lifelong Learning for the 21 Century, 2004.

[7] M. A. Masetla, Examining Challenges in the Implementation of Performance Appraisal on Educators in Shiluvana Circuit, Mopani District, South Africa, University of Venda, Thohoyandou, South Africa, 2018.

[8] N. J. Booyse, "Development of a school-based performance management framework for self-managing schools in South Africa," Unpublished thesis, Unisa, Adelaide, Australia, 2018.

[9] K. A. Hynek, I. Malmberg-Heimonen, and A. G. Tøge, "Improving interprofessional collaboration in Norwegian primary schools: a cluster-randomized study evaluating effects of the LOG model on teachers' perceptions of interprofessional collaboration," Journal of Interprofessional Care, vol. 1, pp. 1-10, 2020.

[10] R. M. Kimeu and S. Maina, "Strategy implementation and performance of commercial banks in Machakos County, Kenya," International academic journal of human resource and business administration, vol. 3, no. 1, pp. 434-450, 2018.

[11] B. C. E. Oguguo, F. A. Nannim, J. J. Agah, C. S. Ugwuanyi, C. U. Ene, and A. C. Nzeadibe, "Effect of learning management system on Student's performance in educational measurement and evaluation," Education and Information Technologies, vol. 26, no. 2, pp. 1471-1483, 2021.
[12] M. J. Mosoge and M. W. Pilane, "Performance management: the neglected imperative of accountability systems in education," South African Journal of Education, vol. 34, no. 1, p. 18, 2014, http://www.sajournalofeducation.co.za.

[13] M. L. Donaldson and H. Peske, Supporting Effective Teaching through Teacher Evaluation: A Study of Teacher Evaluation in Five Charter Schools, Center for American Progress, Washington, NJ, USA, 2010.

[14] S. T. Eric and H. T. John, "Can teacher evaluation improve teaching? Evidence of systematic growth in the effective of midcareer teachers," Evidence Next, vol. 12, no. 4, pp. 78-84, 2012.

[15] J. Y. Jiang, S. E. Sporte, and S. Luppescu, "Teacher perspectives on evaluation reform," Educational Researcher, vol. 44, no. 2, pp. 105-116, 2015.

[16] M. J. Manatos, C. S. Sarrico, and M. J. Rosa, "The integration of quality management in higher education institutions: a systematic literature review," Total Quality Management and Business Excellence, vol. 28, no. 1-2, pp. 159-175, 2017.

[17] Parliamentary Monitoring Group, Report to the Portfolio Committee on the Intergrated Quality Management System (IQMS)Parliamentary Monitoring Group, Cape Town, South Africa, 2016, http://pmg-assets.s3-website-eu-west.

[18] M. F. Maphutha, Intergrated Quality Management System in Sasolburg Primary Schools. http://libserv5.tut.ac.za7780/, 2016.

[19] K. Callahan and L. Sadeghi, "Teacher perceptions of the value of teacher. Evaluations: New Jersey's ACHIEVE NJ. NCPEA," International Journal of Educational Leadership preparation, vol. 1021 pages, 2015.

[20] L. Darling-Hammond, Getting Teacher Evaluations Right, Teachers College Press, New York, NY, USA, 2013.

[21] M. L. Donaldson, So Long, Lake Wabegon Center for American Progress, Washington, NJ, USA, 2009.

[22] D. Weissberg, S. Sexton, J. Mulhern, and D. Keeling, The Widget Effect: Our National Failure to Acknowledge and Act on Differences in Teacher Effectiveness, The New Teacher Project, New York, NY, USA, 2009.

[23] American Federation for Teachers, A Continuous Improvement Model for Teacher Development and EvaluationAmerican Federation for Teachers, Washington, NJ, USA, 2016, http://www.aft.org/pdfs/teachers/.

[24] National Education Association (NEA, 2010).

[25] New Zealand Educational Institute, Performance Management New Zealand Educational Institute, Wellington, New Zealand, 2016, http://www.principallskit.org.nz.

[26] R. J. Marzano, "The two purposes of teacher evaluation," Educational Leadership, vol. 70, no. 3, pp. 14-19, 2010.

[27] C. J. White, Research: A Practical Guide, Ithuthuko Investment, Pretoria, South Africa, 1st edition, 2005.

[28] J. H. MacMillan and S. Schumacher, Research in Education: Evidence-Based Inquiry [with My Education Lab], 2010. 